\title{
Effect of nonthermal plasma treatment on surface chemistry of commercially-pure titanium and shear bond strength to autopolymerizing acrylic resin
}

\author{
Aljomar José Vechiato-Filho ${ }^{\mathrm{a}, *}$, Isabella da Silva Vieira Marques ${ }^{\mathrm{b}}$, Daniela Micheline dos Santos ${ }^{\mathrm{a}}$, \\ Adaias Oliveira Matos ${ }^{\text {b }}$, Elidiane Cipriano Rangel ${ }^{c}$, Nilson Cristino da Cruz ${ }^{\mathrm{c}}$, Valentim Adelino Ricardo Barão ${ }^{\mathrm{b}}$ \\ a Department of Dental Materials and Prosthodontics, Aracatuba Dental School, Univ. Estadual Paulista - UNESP, Aracatuba, Sao Paulo, Brazil \\ b Department of Prosthodontics and Periodontology, Piracicaba Dental School, University of Campinas (UNICAMP), Piracicaba, Sao Paulo, Brazil \\ c Laboratory of Technological Plasmas (LaPTec), Engineering College, Univ. Estadual Paulista - UNESP, Sorocaba, Sao Paulo, Brazil
}

\section{A R T I C L E I N F O}

Article history:

Received 27 May 2015

Received in revised form 2 October 2015

Accepted 3 November 2015

Available online 7 November 2015

\section{Keywords:}

Adhesion

Topic:

Glow discharge

Titanium

Surface characterization

Prosthesis

\begin{abstract}
A B S T R A C T
The effect of nonthermal plasma on the surface characteristics of commercially pure titanium (cp-Ti), and on the shear bond strength between an autopolymerizing acrylic resin and cp-Ti was investigated. A total of 96 discs of cp-Ti were distributed into four groups $(\mathrm{n}=24)$ : Po (no surface treatment), SB (sandblasting), Po + NTP and SB + NTP (methane plasma). Surface characterization was performed through surface energy, surface roughness, scanning microscopy, energy dispersive spectroscopy, and X-ray diffraction tests. Shear bond strength test was conducted immediately and after thermocycling. Surface treatment affected the surface energy and roughness of $\mathrm{cp}$-Ti discs $(P<.001)$. SEM-EDS showed the presence of the carbide thin film. XRD spectra revealed no crystalline phase changes. The SB + NTP group showed the highest bond strength values (6.76 $\pm 0.70 \mathrm{MPa})$. Thermocycling reduced the bond strength of the acrylic resin/cp-Ti interface $(P<.05)$, except for Po group. NTP is an effective treatment option for improving the shear bond strength between both materials.
\end{abstract}

(c) 2015 Elsevier B.V. All rights reserved.

\section{Introduction}

Acrylic resins - polymers based on polymethylmethacrylate (PMMA) - are widely used as a superstructure material for implantsupported fixed dentures [1,2] because of their similarity to oral soft tissues, low cost, biocompatibility, easy handling [3,4], and its assumed "cushion effect" on masticatory loadings to the peri-implant hard tissue [1,5]. Despite these advantages, denture durability might be affected by the adhesion of PMMA to the metal framework [6]. Frameworks of implant-supported fixed dentures are mainly fabricated with commercially pure titanium (cp-Ti) due to advances in the casting procedures [7] and the favorable properties such resistance to corrosion, biocompatibility and relatively low cost [3].

In vitro studies show that acrylic resins have poor bonding to metal alloys [3,6-10]. Failure at the metal-resin interface may lead to significant clinical complications [3,7,10]. In general, the failures are adhesive in nature and allow the micro-leakage of oral fluids, microorganisms and oral debris $[3,7,8]$, resulting in biodegradation of the PMMA material [4]. As a consequence, the strength of this bonding, which is relatively

\footnotetext{
* Corresponding author at: Department of Dental Materials and Prosthodontics, Aracatuba Dental School, Univ. Estadual Paulista - UNESP, Jose Bonifacio, 1153, Aracatuba, Sao Paulo ZIP code: 16015-050, Brazil.

E-mail address: aljomarvechiatoflo@gmail.com (A.J. Vechiato-Filho).
}

low, decreases, and fractures of the resin material may occur [8]. This might be the major factor that is responsible for the high incidence (from $43.75 \%$ to $66.6 \%$ ) of resin superstructure fractures (most common clinical problem) and prosthesis maintenance after 15 years of follow up $[11,12]$.

The use of autopolymerizing acrylic resins is considered to be an economical and non-time-consuming method for performing repairs of dentures with PMMA-based materials as superstructures $[6,9,10]$. However, the resin-metal interface may not be durable because the strength of this chemical bonding decreases $(\approx 60 \%)$ in the short-term [6]. Therefore, developing treatments to improve the bonding of resins to metal alloys has been the goal of some studies $[3,7,8]$.

Several methods for improving the bonding between acrylic resin superstructures and metal frameworks have been proposed $[6-8,10]$; sandblasting with aluminum oxide particles $\left(\mathrm{Al}_{2} \mathrm{O}_{3}\right)$ is one of the most effective methods for increasing the bond strength between these two materials [8]. In addition, some studies have used nonthermal plasma (NTP) treatments to improve the bonding values in dental ceramics; these treatments are considered an alternative solution for the clinical problems related to adhesion [13-17]. The plasma technique may increase the adhesion of a substrate to new molecules through improving its wettability by inducing strong chemical bonds and new chemically reactive sites [13-17]. NTP treatments are widely used in industry [18, 19], and a previous study demonstrated that the plasma created by 
methane gas $\left(\mathrm{CH}_{4}\right)$ associated with ion bombing through high-energy electro-pulses has a satisfactory result for improving the contact angle and free surface energy of some metals (Ti and Ti-6Al-4V alloy) and polymers (Teflon, silicone rubber, nylon, polyvinyl-chloride and polyurethane) used in biomedical devices [17]. Moreover, it has been shown that high-energy electro-pulsing treatment also improves the mechanical properties of Ti-6Al-4V (i.e. ductility and strengthtoughness), as well as its corrosion behavior [20,21].

Because the $\mathrm{CH}_{4}$ plasmas might improve the Ti wettability, it is assumed that they might be used to improve the adhesion between this material and other materials. However, to the best of the author's knowledge, no study evaluated the NTP created by $\mathrm{CH}_{4}$ to improve the chemical bonding of PMMA to $\mathrm{cp}-\mathrm{Ti}$. Artificial aging through thermocycling is necessary for evaluating the performance of an adhesive interface because this condition affects the bond strength of two different materials and is considered a clinically relevant aging parameter [22,23]. Thus, the aims of this study were as follows: (1) to characterize the surface of cp-Ti discs with or without NTP treatment based on surface energy, scanning electronic microscopy associated with energy dispersive spectroscopy (SEM-EDS), and X-ray diffraction (XRD) analyses; and (2) to evaluate whether the NTP treatment improves the shear bond strength between an autopolymerizing acrylic resin and cp-Ti before and after thermocycling. The tested hypotheses were that the NTP treatment would modify the surface characteristics of cp-Ti and would improve the shear bond strength between PMMA and cp-Ti.

\section{Materials and methods}

\subsection{Experimental design}

The materials used in the present study are listed in Table 1. A total of 96 discs of $\mathrm{cp}$-Ti ( $8 \mathrm{~mm}$ in diameter $\times 2 \mathrm{~mm}$ in thickness) that were grade IV according to the American Society for Testing Materials (ASTM) were obtained (Conexão Sistemas de Prótese Ltd., Arujá, SP, Brazil). The discs were randomly divided into 4 groups $(n=24)$ as follows:

- Po group = control; no surface treatment was conducted.

- $\mathrm{SB}$ group = sandblasting with aluminum oxide particles $\left(\mathrm{Al}_{2} \mathrm{O}_{3}\right)$.

- NTP group = nonthermal plasma treatment.

- $\mathrm{SB}+\mathrm{NTP}$ group = sandblasting with $\mathrm{Al}_{2} \mathrm{O}_{3}+$ nonthermal plasma treatment.

The cp-Ti discs were positioned in the center of cylinder cups (SamplKups; Buheler, Lake Bluff, IL, USA) and embedded in an autopolymerizing acrylic resin (JET, Classico, Sao Paulo, SP, Brazil). After acrylic resin polymerization, the embedded cp-Ti discs were sequentially polished with 320-, 400- and 600-grit abrasive papers (CarbiMet 2; Buehler, Lake Bluff, IL, USA) with constant water irrigation in a semi-automatic polishing machine (Aropol 2V; Arotec, Cotia, SP, Brazil). Then, the cp-Ti discs from the SB and SB + NTP groups $(\mathrm{n}=$ 48) were sandblasted with $120 \mu \mathrm{m}$ particles of $\mathrm{Al}_{2} \mathrm{O}_{3}$ (Polidental Industria Comercio Ltd., Cotia, SP, Brazil) deposited from a $50 \mathrm{~mm}$ distance with $90^{\circ}$ of angulation using $0.45 \mathrm{MPa}$ bar pressure for $30 \mathrm{~s}$ [24]. The cp-Ti discs were then cleaned with alternate ultrasonic baths in deionized water (1 min), 99.3\% ethyl alcohol (5 min), and again in deionized water $(1 \mathrm{~min})$ to remove the smear layer from the specimen surface [14].

\subsection{NTP treatment}

The cp-Ti discs from the NTP and SB + NTP groups were subjected to NTP treatment. Plasma treatment was performed inside a stainless steel chamber by using a custom-made reactor from the Technological Plasma Laboratory (LaPTec; Sao Paulo State University - Engineering College, Sorocaba, SP, Brazil) evacuated to a background pressure of $3.6 \times 10^{-2}$ Torr. Before the $\mathrm{CH}_{4}$ plasma depositions, argon ( $\mathrm{Ar}$ ) gas was admitted into the chamber and cleaning plasmas were prepared at a radiofrequency of $13.56 \mathrm{MHz}(70 \mathrm{~W}$ ) applied in the sampleholder for $600 \mathrm{~s}$ under a constant work pressure of $1.67 \times 10^{-1}$ Torr. Immediately after this cleaning procedure, Ar was stopped, and the chamber was evacuated again to the background pressure. Then, the plasma depositions were prepared from mixtures of $92 \%$ of $\mathrm{CH}_{4}$ gas and $8 \%$ of $\mathrm{Ar}$ at $13.56 \mathrm{MHz}(70 \mathrm{~W})$ applied in the superior electrode for $600 \mathrm{~s}$ under $1.67 \times 10^{-1}$ Torr. The plasmas were created with the ion implantation and deposition by immersion in plasmas (IIDIP) technique using the following conditions: $3.12 \mathrm{kV}, 299 \mathrm{~Hz}, 25 \mu \mathrm{s}$ and $0.75 \%$ of working cycle. In IIDIP, high pulses of negative tension are applied in the sample-holder so that ions are accelerated and implanted (ionic bombing) on the surface and subsurface of the cp-Ti discs, creating thin-films with improved mechanical and tribological properties. The $\mathrm{cp}$-Ti discs were removed from the stainless glass chamber at a temperature of $33^{\circ} \mathrm{C}$, thereby preserving the surface integrity.

\subsection{Surface energy}

Three cp-Ti discs from each group were subjected to surface energy analysis using a goniometer (Ramé-Hart 100-00; Ramé-Hart Instrument Co., Succasuanna, NJ, USA). A $0.5-\mu \mathrm{L}$ drop of deionized water (polar component) and diiodomethane (dispersive component) was dropped through a $50-\mu \mathrm{L}$ glass syringe. The contact angle was calculated by means of the Young equation: $\gamma_{s v}=\gamma_{s l}+\gamma_{l v} \cos \theta$; where $\theta$ is the contact angle and $g$ is the surface energy of the solid-vapor (sv), solid-liquid (sl) and liquid-vapor (lv) interfaces. The surface energy was calculated using the Owens-Wendt-Rabel-Kaelble method. The relationship between the contact angle and the surface energy was evaluated using the formula $\gamma \mathrm{L}=\gamma^{\mathrm{D}} \mathrm{L}+\gamma^{\mathrm{P}} \mathrm{L}$, where $\gamma \mathrm{L}$ is the total surface energy, $\gamma^{\mathrm{D}} \mathrm{L}$ is the dispersive (apolar) component and $\gamma^{\mathrm{P}} \mathrm{L}$ is the polar component. Ten measurements were performed per disc $(n=100$ total readings).

\subsection{Surface roughness}

Surface roughness was measured with a profilometer (Dektak D150; Veeco, Plainview, NY, USA). Three discs from each experimental group were used for the roughness test. The Ra (arithmetic mean of surface roughness), $\mathrm{Rq}$ (root-mean-square roughness), $\mathrm{Rz}$ (height between the maximum and minimum profiles over evaluation length), and Rt (vertical distance between the highest peak and the deepest pit) values were obtained by using a cutoff of $500 \mu \mathrm{m}$ for $12 \mathrm{~s}$. Three readings were taken: 1 at the center of the specimen and 2 parallel readings to the

Table 1

Materials used for the present study.

\begin{tabular}{|c|c|c|c|}
\hline Material (identification) & Composition (in \% of weight) & Batch number & Manufacturer \\
\hline Commercially pure titanium (cp-Ti) (grade IV) & $0.03 \mathrm{~N}, 0.1 \mathrm{C}, 0.0125 \mathrm{H}, 0.3 \mathrm{Fe}, 0.25$ O, balance Ti & 142440 & Conexao Sistemas de Protese Ltd. \\
\hline Autopolymerizing acrylic resin (JET) & $\begin{array}{l}\text { Powder: methyl ethyl methacrylate copolymer, organic pigments } \\
\text { (medium pink hue), peroxide } \\
\text { Liquid: methyl methacrylate monomer, dimethacrylate }\end{array}$ & 015070 & Classico \\
\hline Methane $\left(\mathrm{CH}_{4}\right)$ & $100 \%$ methane vapor & USLY001027 & White Martins \\
\hline Argon $(\mathrm{Ar})$ & $100 \%$ argon vapor & $15116 / 12$ & White Martins \\
\hline
\end{tabular}


right and left of center. Then, the average was calculated. Initial results were obtained in angstroms and converted to micrometers $(\mu \mathrm{m})$.

\subsection{SEM-EDS}

One cp-Ti disc from each group was submitted to SEM (JSM 610LA; JEOL, Tokyo, Japan). Discs were gold-sputtered at the moment of the reading. Images were captured at $3.000 \times$, magnifications. Simultaneously, the same disc that was used for the SEM analysis was submitted to elemental chemical composition analysis at the order of $1 \mu \mathrm{m}^{3}$ (cubic micrometer) through EDS. The goal of EDS was to characterize the principal chemical elements of the disc surface before and immediately after NTP treatment. The configurations used for EDS analysis were as follows: $3 \mathrm{kV}$ of accelerated voltage, working distance (WD) of $9 \mathrm{~mm}$ and a spot size (SS) of 75 .

\subsection{Analysis of crystal structure}

The same cp-Ti disc used for the SEM-EDS analysis was used to characterize the crystal structure of the tested Ti discs using a highresolution X-ray diffractometer (Panalytical X'Pert Powder; PANalytical, Almelo, Overijssel, Netherlands). The crystal structure was measured using $\mathrm{Cu}$ Ka radiation at $45 \mathrm{kV}$ and $40 \mathrm{~mA}$. The spectrum was recorded from 20 to $90^{\circ}$ with an incident angle of $5^{\circ}$ and a scan speed of $0.01^{\circ}$ per second.

\subsection{Shear bond strength test}

Eighty $\mathrm{cp}$-Ti discs were subjected to the shear bond strength test. Thus, a silicone mold (Zetalabor; Zhermack S.p.A., Sao Paulo, SP, Brazil) with a perforation in its center $(5 \mathrm{~mm}$ in diameter and $2.5 \mathrm{~mm}$ in depth) was used to pour the tested autopolymerizing acrylic resin. The silicone mold was fixed to the embedded cp-Ti disc with a cyanoacrylate adhesive (Super Bonder; Loctite Henkel Ltd., Sao Paulo, SP, Brazil). The tested autopolymerizing acrylic resin was manipulated according to the manufacturer's instructions ( $1.097 \mathrm{~g} / 0.5 \mathrm{~mL}$ of mixing ratio). Then, the resin was poured directly into the perforation of the silicone mold. This assembly was pressure-cured under $245 \mathrm{kPa}$ for patronization of the surface contact area until complete polymerization of acrylic resin was achieved. Then, the silicone mold was carefully removed $[25,26]$.

The shear bond test was performed on a Universal testing machine (Instron Model 4400 Universal Testing System; Instron Corporation, Norwood, MA, USA) at a cross-head speed of $1 \mathrm{~mm} / \mathrm{min}[23,24]$. The load at fracture was recorded in MPa. Half of the cp-Ti discs were immediately used for shear bond strength test. The other half of the $\mathrm{cp}-\mathrm{Ti}$ discs were subjected to thermocycling in alternate baths of $5 \pm 1{ }^{\circ} \mathrm{C}$ and $55 \pm 1{ }^{\circ} \mathrm{C}$ for $30 \mathrm{~s}$ per bath ( 1 cycle) until 2000 cycles prior to the shear bond strength test. All cp-Ti discs were stored in distilled water for $50 \mathrm{~h}$ prior the shear bond strength test.

\subsection{Analysis of bonding failure}

The pattern of bonding failure between the autopolymerizing acrylic resin and the cp-Ti discs was evaluated through scanning microscopy of $10 \times$ magnifications. The failure pattern was quantified and classified into three categories: adhesive, the failure at the $\mathrm{cp}$-Ti/acrylic resin interface; cohesive, the failure within the acrylic resin; and mixed, the adhesive-cohesive failure. Representative images of each group were obtained with the same magnifications mentioned above.

\subsection{Statistical analysis}

Data on the surface energy and surface roughness were examined by one-way analysis of variance (ANOVA) (factor:surface). Data on the shear bond strength were analyzed by two-way ANOVA (factor 1:surface; factor 2:thermocycling). Tukey HSD test was used to compare the mean values among the groups. T-test was used to compare the shear bond strength value before and after thermocycling within the group $(\alpha=.05)$ (SPSS version 20.0 - Statistical Package for the Social Sciences, IBM Corp, Armonk, NY, USA). With 10 samples per group in the shear bond strength test, a large size effect was obtained: Partial Eta Squared $F(3,69)=160.037, P<.0001, \eta_{\mathrm{p}}^{2}=.874$. and Cohen's effect size $d=10.51$, effect size $r=.982$.

\section{Results}

\subsection{Surface characterization}

The one-way ANOVA results indicated that the surface treatment significantly affected the surface energy of the $\mathrm{cp}$-Ti discs ( $\mathrm{F}=71.378$ and $P<.001$ ). Fig. 1 displays the polar and dispersive components of the groups, before and after NTP treatment. There was an increase of both components for the Po + NTP group whereas those components were slightly decreased in the SB + NTP group. However, there was no significant difference between the groups $(P>.05)$. There was a significant difference only between the Po and SB groups $(P<.001)$. Representative images of the water contact angle were displayed in Fig. 2 , indicating a reduction to $0^{\circ}$ after NTP treatment only for the Po + NTP group.

Moreover, the one-way ANOVA for surface roughness indicated that the surface treatment factor significantly affected the $\mathrm{Ra}(\mathrm{F}=61.241$ and $P<.001)$, Rq $(\mathrm{F}=38.726$ and $P<.001)$, Rt $(\mathrm{F}=30.728$ and

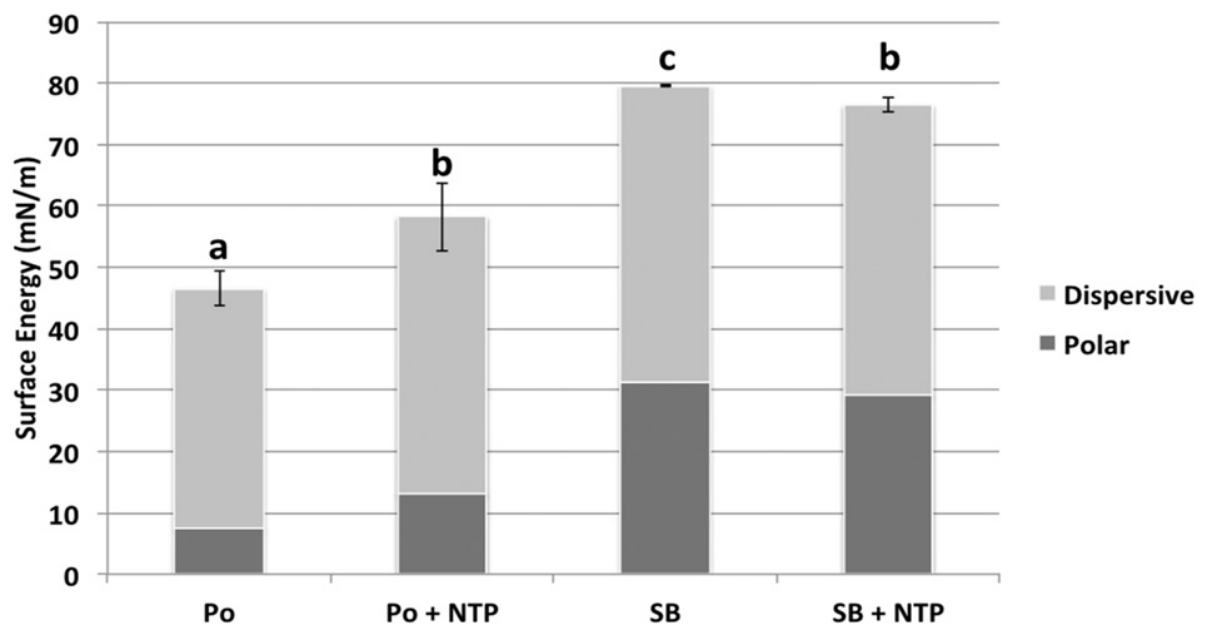

Fig. 1. Main polar and dispersive components of Po, Po + NTP, SB and SB + NTP groups. Different letters represent significant differences $(P<0.001$, Tukey HSD test). 
A

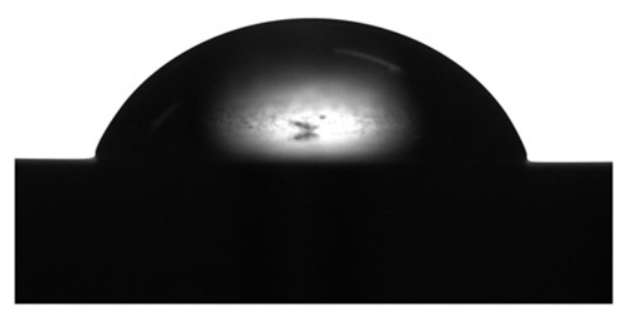

C

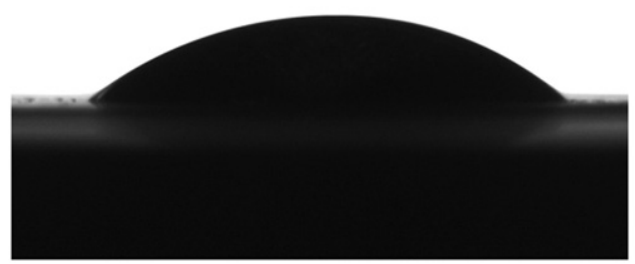

B

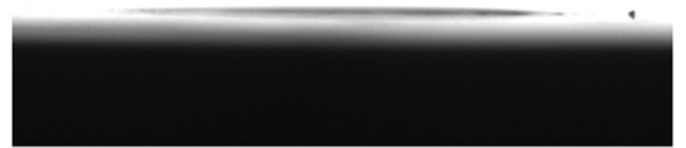

D

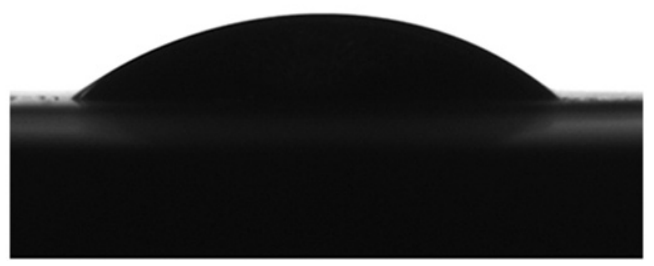

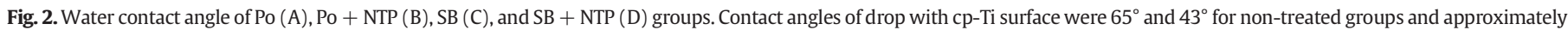
$0^{\circ}$ and $20^{\circ}$ for nonthermal plasma groups.

$P<.001)$ and $\mathrm{Rz}(\mathrm{F}=70.422$ and $P<.001)$ parameters. However, there was no significant difference between the Po and Po + NTP groups regarding all of the tested parameters (Fig. 3). The cp-Ti discs from SB and SB + NTP group showed the greatest surface roughness values $(P<.05)$.

SEM-EDS images are displayed in Fig. 4. The cp-Ti disc from the Po group showed a homogenous surface and high amounts of titanium (Ti) with the presence of carbon (C). The surface of the disc from the SB group was almost entirely modified by the sandblasting, which displays an irregular deep and coarse surface. In addition, EDS graphics display a decrease in the amount of Ti and the presence of aluminum ( $\mathrm{Al}$ ), C and oxygen $(\mathrm{O})$ for the SB group. The disc from the SB + NTP group showed a reduction in the surface irregularities after the NTP treatment. The EDS analysis showed the presence of $\mathrm{C}$ and nitrogen $(\mathrm{N})$ for all of the treated cp-Ti discs. Discs subjected to the NTP treatment showed lower levels of $\mathrm{Ti}$ and higher levels of $\mathrm{O}$ than the other groups. Moreover, EDS revealed the presence of additional elements such as sodium (Na) and fluorine $(\mathrm{F})$. For the NTP treated groups, the carbide thin film was absent from cracks, adhered to the cp-Ti surface, and showed no discontinuity.

Fig. 5 displayed the XRD spectra. No new peaks were detected in any of the experimental groups. The peak changes observed in the SB and SB + NTP groups occurred because of the minerals from the blasting powder particles. The deposited carbide thin film was amorphous because no characteristic peaks were observed in the XRD analysis.

\subsection{Shear bond strength}

For the shear bond strength, two-way ANOVA revealed a significant difference for surface ( $d f=3, \mathrm{~F}=467.385, P<.001$ ), thermocycling $(d f=1, \mathrm{~F}=77.149, P<.001)$ and their interaction $(d f=3, \mathrm{~F}=$ $15.430, P<.001$ ). Table 2 displays the means and standard deviations of the shear bond strength values for the groups. NTP treatment significantly increased the shear bond strength values of polished and sandblasted cp-Ti discs both before and after thermocycling $(P<.05)$. $\mathrm{SB}+$ NTP exhibited the greatest shear bond strength value $(P<.05)$.

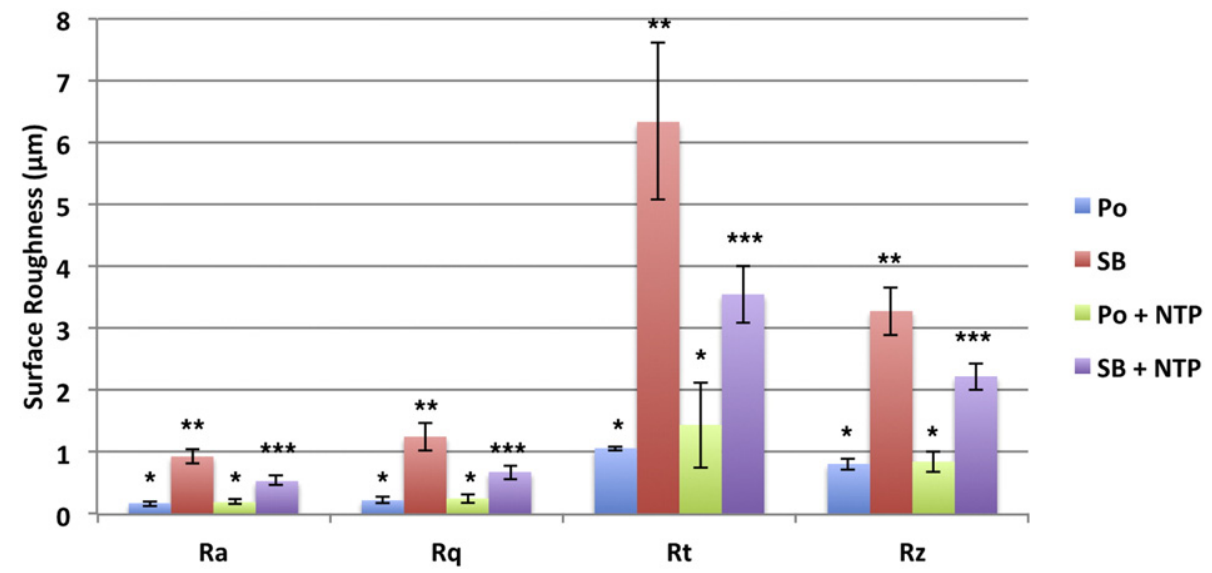

Fig. 3. Main surface roughness (Ra, Rq, Rt and Rz) of groups. Asterisks $\left({ }^{* * *}\right.$ and $\left.{ }^{* * *}\right)$ represent significant differences $(P<0.001$, Tukey HSD test). 
Thermocycling significantly reduced the shear bond strength of all of the groups $(P<.05)$ except for the Po group $(P>.05)$.

Failures modes of all the groups are shown in Table 2. An increase in mixed failures after NTP treatment for the Po + NTP (30\%) and SB + NTP groups (70\%) was noted. However, there was a decrease of this type of failure mode for both groups ( $17 \%$ and $40 \%$, respectively) after thermocycling. Even after thermocycling, both groups exhibited a higher number of mixed failures in comparison to the Po and SB groups. Representative SEM images of failure modes are displayed in Fig. 6.

\section{Discussion}

The tested hypotheses of the present study were accepted once the NTP treatment modified the surface characteristics of cp-Ti and
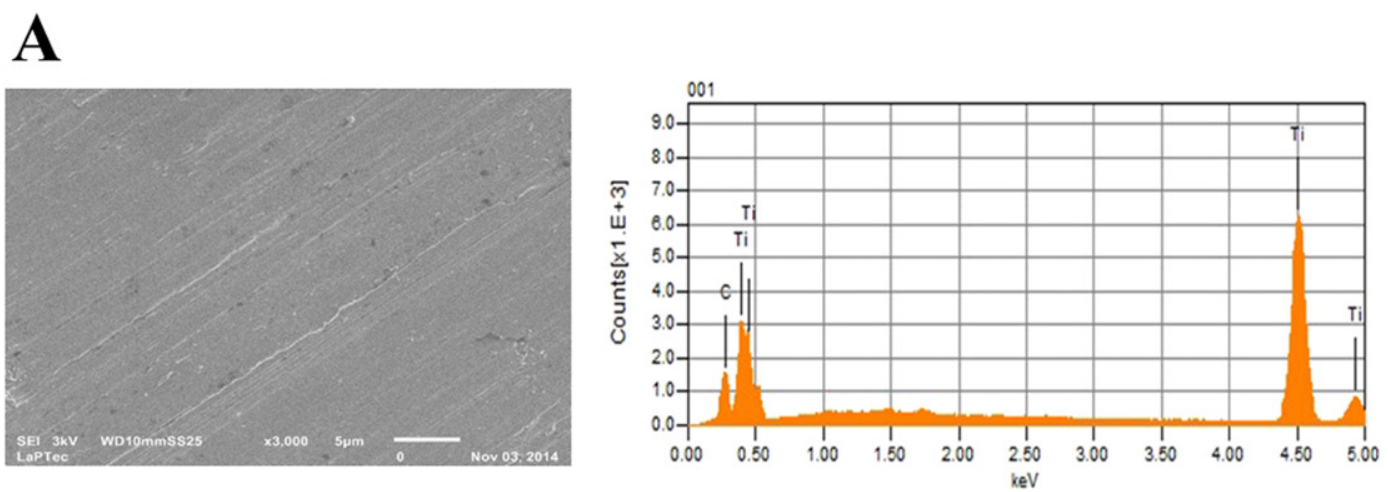

B
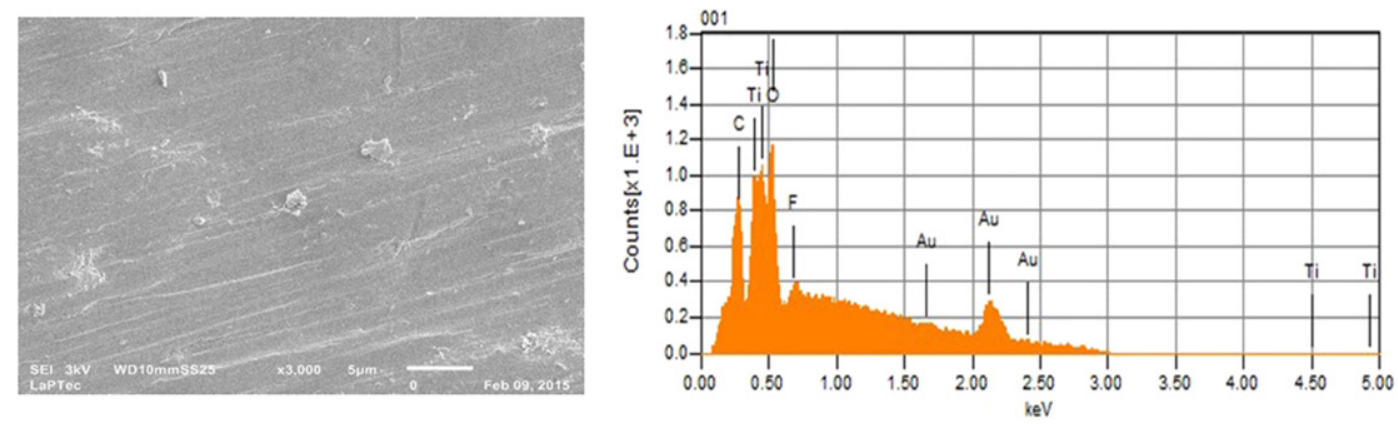

C
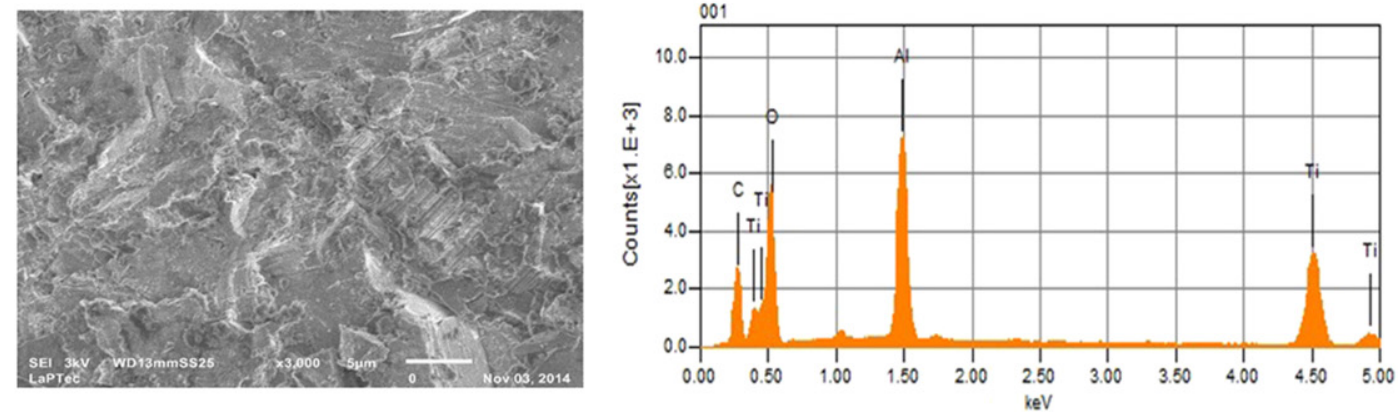

\section{D}
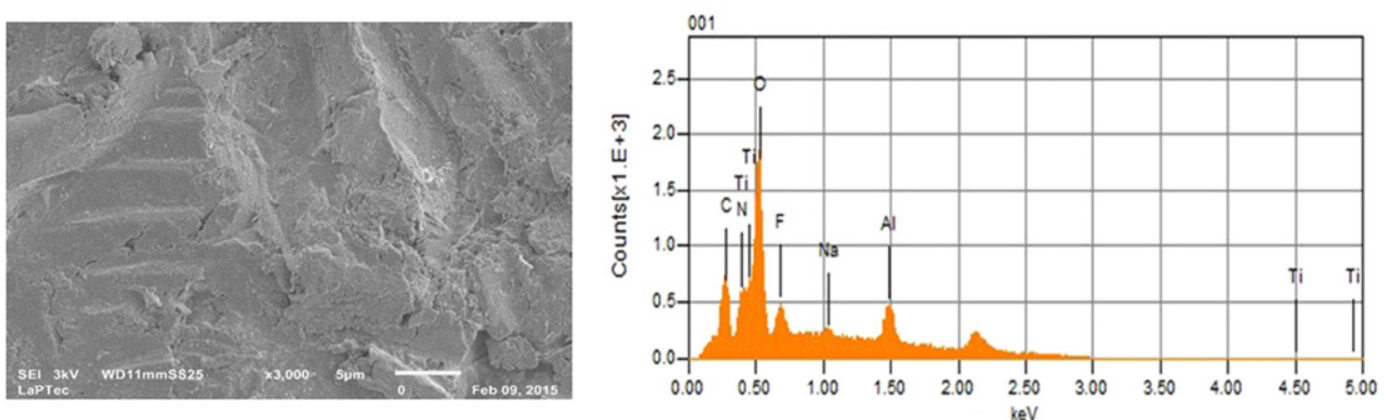

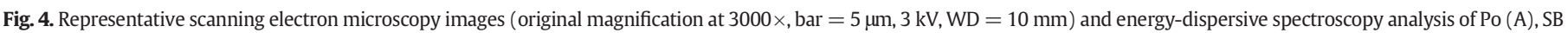
(B), Po + NTP (C) and SB + NTP (D) groups. 
improved the shear bond strength of the tested acrylic resin to cp-Ti, before and after the thermocycling challenge.

\subsection{Surface characterization}

The deposition of the $\mathrm{CH}_{4}$ (carbide-based) thin film was responsible for the reduction in the water contact angle on the surface of the Po + NTP group [14,15]. Probably, the IIDIP plasma deposition technique, in which ions from the plasma generation are accelerated by a negative potential (sample-holder) and implanted by bombing in the cp-Ti surface creates a surface with high energy potential and might be responsible for this dramatic reduction in the water contact angles [17]. However, once the determination of the surface energy requires angles to be at least $10^{\circ}$, the values used for this calculation will be higher than those presented in Fig. 2(C) [14]. The water contact angle was not reduced for the SB and SB + NTP groups. Some authors propose that the sandblasting procedure with $\approx 120 \mu \mathrm{m}$ particles of $\mathrm{Al}_{2} \mathrm{O}_{3}$ produces a net negative charge on the cp-Ti surface because the blasting of the powder particles might remove the oxide layer $\left(\mathrm{TiO}_{2}\right)$ and create a slight hydrophobicity pattern on the cp-Ti surface. This fact explains the nonreduction of the water drops even after the NTP treatment [27-29].

The gritting effect from the sandblasting procedure also induces surface damage by removing portions of the external layer of the cp-Ti surface [3,27], which is responsible for the highest values for $\mathrm{cp}$-Ti roughness in the SB group compared to the other groups. Moreover, the sandblasting procedure promoted the highest surface energy values for the SB and SB + NTP groups compared to the other groups. In fact, the irregularities on the Ti surface were filled with water droplets (polar component of the Owens-Wendt equation) $[14,15,30]$, reducing the surface contact angle and increasing the surface energy values. Furthermore, the $\mathrm{Al}_{2} \mathrm{O}_{3}$ particles increased the surface contact area by promoting better surface wettability, which is also determined by the roughness (dispersive component of the Owens-Wendt equation) [15]. The association of both factors may be the driving force toward higher surface energy results in the sandblasted groups than the other groups, even with water contact angles more than $0^{\circ}$.

However, the lower surface roughness in the SB + NTP group compared to the SB group might be explained by the thin film deposited on the cp-Ti surface, which sealed the irregularities created by the sandblasting procedure [14]. This fact also justifies the slight reduction in the surface energy of the SB + NTP group because the $\mathrm{CH}_{4}$ thin film might have decreased the wettability, not only because of the reduced surface roughness but also because of the smaller irregularities on the cp-Ti surface, which are filled with smaller amounts of water [30]. Such affirmation is consistent with the SEM images where the NTP treatment sealed some of the irregularities created by the sandblasting procedure on the $\mathrm{cp}$-Ti surface. Moreover, a reduction in the Ti levels and an increase in the C content indicate that the carbide-based thin film deposition was effective. The presence of $\mathrm{O}$ and $\mathrm{N}$ elements is most likely due to adsorption from the residual atmosphere because $\mathrm{Ti}$ is a strong getter [17]. The presence of $\mathrm{F}$ might be confused for the iron ( $\mathrm{Fe}$ ) element by the EDS tester and is most likely incorporated on the Ti surface during the treatment as a consequence of the plasma interactions with the glass chamber and metallic parts [31]. In addition, the Na may represent some impurity. Thus, these two elements were disregarded from the data analysis.

No alteration in the crystalline phase of the cp-Ti surface of the experimental groups was noted. The NTP treatment applied in the present study showed no phase transformation and was considered amorphous. The amorphous nature of the deposited thin film is a result of the low temperature of the deposition process [32], so that no thermal stress on the Ti material was created. Thus, the NTP treatment is assumed to not induce a corrosion process on the Ti material because thermal fluctuations also play a role in this process $[33,34]$.

\subsection{Shear bond strength}

In this study, thermocycling was used to verify the quality and durability of the tested surface treatments. Artificial aging allows the water penetration at the resin-metal interface $[3,8,9]$ and also induces stress in the acrylic resins [4], which decreases the bond strength. The physical and the chemical alterations created by sandblasting and/or the NTP treatment might be one of the factors that are responsible for the higher bond strength results in the Po + NTP, SB and SB + NTP groups. Thus, it can be assumed that the NTP treatment achieved bond quality because the Po + NTP and the SB + NTP groups showed the highest shear bond strength values after the thermocycling. These results might be obtained because carbide-based thin film have unsaturated $\mathrm{C}-\mathrm{C}$ bonds and additional functional groups $(\mathrm{C}-\mathrm{O}, \mathrm{C}-\mathrm{OH})$ that establish strongly stable secondary chemical reactions with the polymeric chains of the acrylic material, resulting in a resin-metal interface that is resistant to the hydrolysis of water $[14,15,17]$. This fact also explains the increase in the percentage of mixed failure in the Po + NTP and SB + NTP groups.

In spite NTP resulted in higher bond strength results, the groups subjected to such experimental treatment do not show a clinically acceptable strength (10 MPa) [35]. However, the extrapolation of such value to the clinical situation should be performed with caution since the bond strength could be enhanced by surface imperfections such as grooves created by sandblasting or retentive features that are performed on the metallic infrastructure of full-arch implantretained prostheses. Regardless these conflicting results, our bond strength results are similar to other published data [36-38]. Moreover, the carbon coating we tested is known to be useful for other goals, such as improving osteoblasts adhesion [39,40]. To the best of the author's knowledge, this is the first approaching for enhancing the adhesion between metallic substrates and acrylics by using theses thin-films.

The present study had some limitations, including the analysis of only one type of acrylic resin among all the different types and brands available on the market. However, the results suggest that the experimental treatment might produce promising results with the other types of acrylics because autopolymerizing acrylic resins

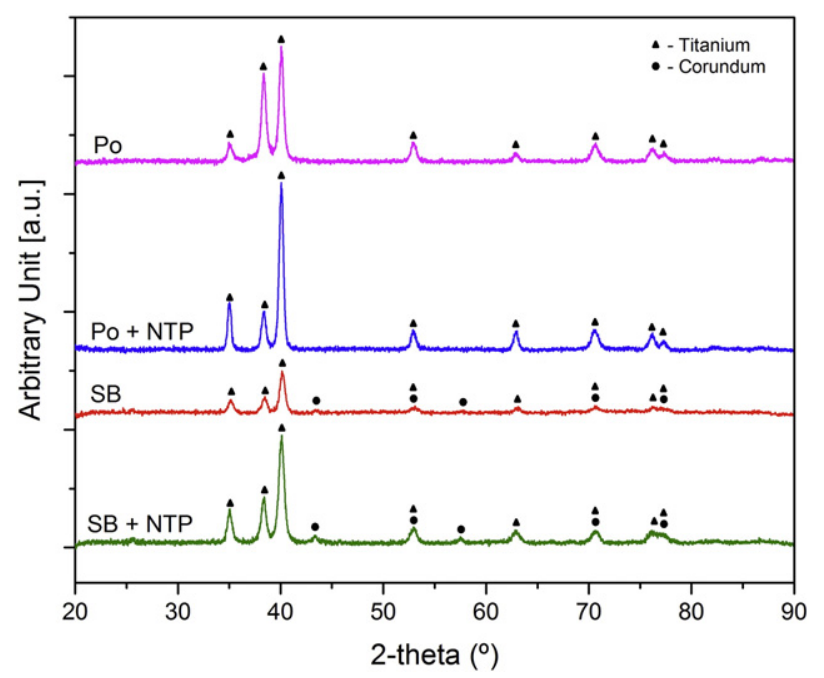

Fig. 5. XRD patterns of Po (A), Po + NTP (B), SB (C) and SB + NTP (D) groups. Note that NTP treatment did not alter the crystalline structure of $\mathrm{cp}$-Ti and did not deposit a crystalline layer (characterizing a nonthermal plasma). 
Table 2

Means and standard deviations of the shear bond strength (in MPa) and failure mode of groups.

\begin{tabular}{|c|c|c|c|c|}
\hline \multirow[t]{2}{*}{ Group } & \multirow[t]{2}{*}{ Initial } & \multicolumn{2}{|c|}{ Shear bond strength (MPa) } & \multirow[t]{2}{*}{ Failure pattern } \\
\hline & & Failure pattern & After thermocycling & \\
\hline Po & $0.29(0.14)^{\mathrm{Aa}}$ & $100 \%$ adhesive & $0.20(0.07)^{\mathrm{Aa}}$ & $100 \%$ adhesive \\
\hline Po + NTP & $1.21(0.26)^{\mathrm{Ba}}$ & $\begin{array}{l}70 \% \text { adhesive } \\
30 \% \text { mixed }\end{array}$ & $0.77(0.09)^{\mathrm{Bb}}$ & $\begin{array}{l}83 \% \text { adhesive } \\
17 \% \text { mixed }\end{array}$ \\
\hline SB & $5.58(0.78)^{\mathrm{Ca}}$ & $\begin{array}{l}90 \% \text { adhesive } \\
10 \% \text { mixed }\end{array}$ & $3.79(0.80)^{\mathrm{Cb}}$ & $\begin{array}{l}90 \% \text { adhesive } \\
10 \% \text { mixed }\end{array}$ \\
\hline $\mathrm{SB}+\mathrm{NTP}$ & $6.76(0.70)^{\mathrm{Da}}$ & $\begin{array}{l}30 \% \text { adhesive } \\
70 \% \text { mixed }\end{array}$ & $4.68(0.40)^{\mathrm{Db}}$ & $\begin{array}{l}45 \% \text { adhesive } \\
55 \% \text { mixed }\end{array}$ \\
\hline
\end{tabular}

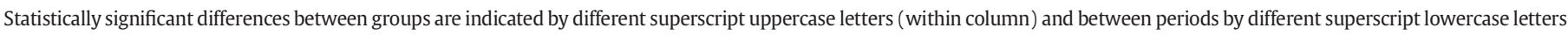
(within row).

are less ideal than the thermopolymerizing acrylic resins (by heat of microwave energy). Moreover, the EDS analysis was conducted only in one cp-Ti disc. Therefore, further investigations are warranted to validate this finding. The artificial aging profile was implemented to evaluate the long-term durability, stability, and hydrolytic degradation of the resin-metal bonding interface, and it might be an advantage compared to other studies that evaluate only the $24-\mathrm{h}$ storage adhesion [22].

A

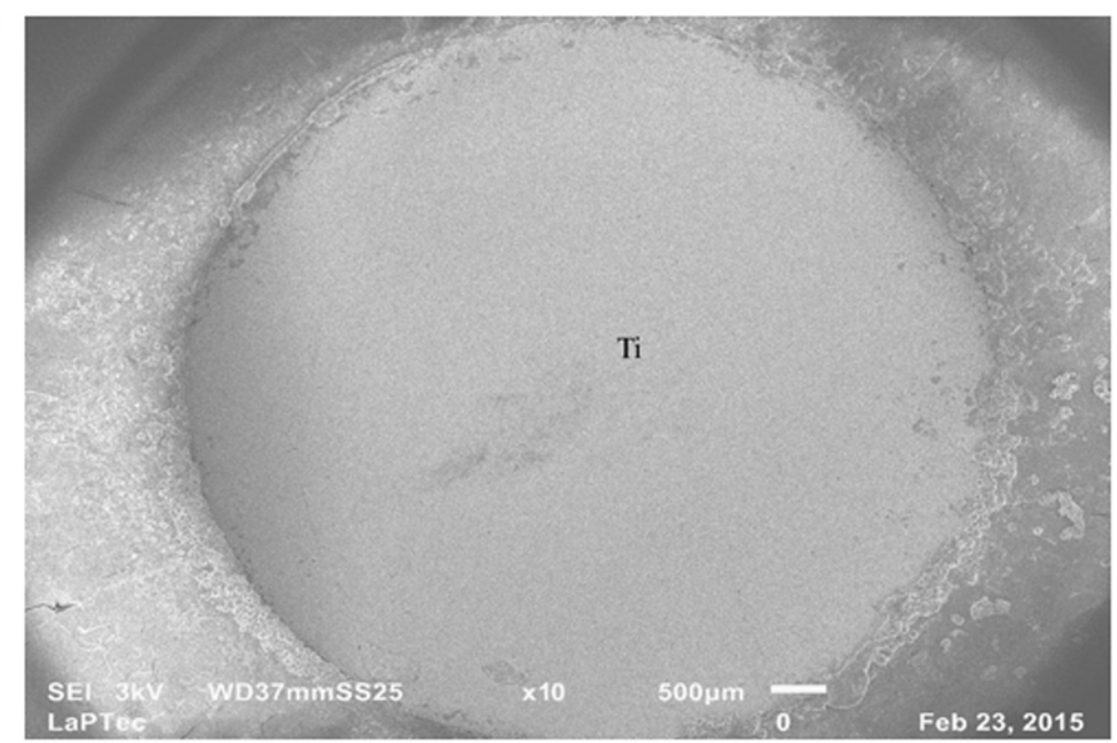

B

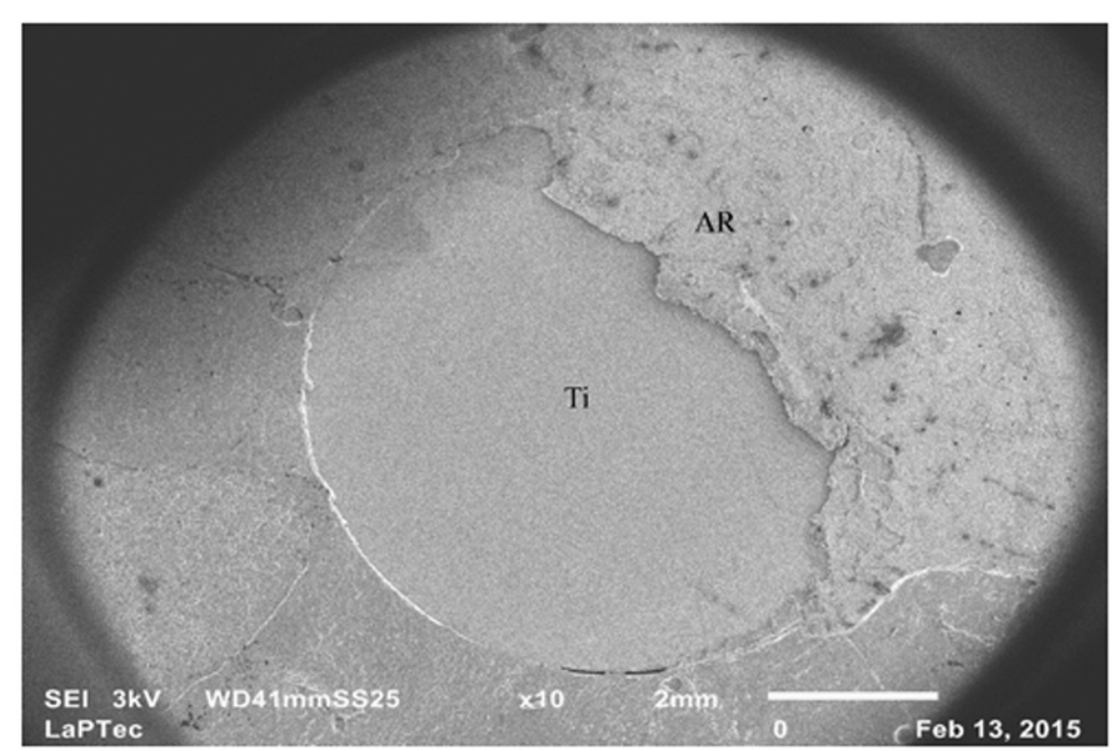

Fig. 6. Representative SEM micrographs of adhesive failure mode (A) and mixed failure mode (B). Original magnification at $10 \times$, bar $=2 \mathrm{~mm}, 15 \mathrm{kV}$, $\mathrm{WD}=41 \mathrm{~mm}$. 


\section{Conclusion}

Within the limitations of this in vitro study, the following conclusions were drawn:

1. NTP treatment with $\mathrm{CH}_{4}$ plasma enhanced the surface energy of the cp-Ti surface, did not alter the surface roughness, and the carbide thin film deposited showed a homogenous pattern with increased $\mathrm{C}$ and $\mathrm{O}$ amounts.

2. NTP treatment improved the shear bond strength of the autopolymerizing acrylic resin to the $\mathrm{cp}$-Ti material, even after the thermocycling challenge. Thus, it might be a solution for the debonding of the superstructure material of the implant-supported fixed dentures.

\section{Acknowledgments}

The authors thank Rafael Parra Ribeiro from the Laboratory of Technological Plasmas (LaPTec, Sorocaba, Sao Paulo, Brazil) for his significant contributions to the SEM, EDS and XRD analyses. The authors also thank Conexao Sistemas de Protese Ltd. for donating the titanium disks.

\section{References}

[1] M.B. Ferreira, V.A. Barão, L.P. Faverani, A.C. Hipólito, W.G. Assunção, The role of superstructure material on the stress distribution in mandibular full-arch implantsupported fixed dentures. A CT-based 3D-FEA, Mater. Sci. Eng., C 35 (2014) 92-99.

[2] P.I. Brånemark, B.O. Hansson, R. Adell, U. Breine, J. Lindström, O. Hallén, A. Ohman, Osseointegrated implants in the treatment of the edentulous jaw. Experience from a 10-year period, Scand. J. Plast. Reconstr. Surg. Suppl. 16 (1977) 1-132.

[3] M. Bulbul, B. Kesim, The effect of primers on shear bond strength of acrylic resins to different types of metals, J. Prosthet. Dent. 103 (2010) 303-308.

[4] A.F. Bettencourt, C.B. Neves, M.S. de Almeida, L.M. Pinheiro, S.A. Oliveira, L.P. Lopes, M.F. Castro, Biodegradation of acrylic based resins: a review, Dent. Mater. 26 (2010) e171-e180.

[5] Y. Ciftçi, S. Canay, The effect of veneering materials on stress distribution in implantsupported fixed prosthetic restorations, Int. J. Oral Maxillofac. Implants 15 (2000) 571-582.

[6] S. Banerjee, R.L. Engelmeier, K.L. O'Keefe, J.M. Powers, In vitro tensile bond strength of denture repair acrylic resins to primed base metal alloys using two different processing techniques, J. Prosthodont. 18 (2009) 676-683.

[7] H.P. Lim, S.S. Kim, H.S. Yang, M.S. Vang, Shear bond strength and failure types of polymethyl methacrylate denture base resin and titanium treated with surface conditioner, Int. J. Prosthodont. 23 (2010) 246-248.

[8] Y. Matsuda, H. Yanagida, T. Ide, H. Matsumura, N. Tanoue, Bond strength of poly(methyl methacrylate) denture base material to cast titanium and cobalt-chromium alloy, J. Adhes. Dent. 12 (2010) 223-229.

[9] N. Tanoue, Y. Matsuda, H. Yanagida, H. Matsumura, T. Sawase, Factors affecting the bond strength of denture base and reline acrylic resins to base metal materials, J. Appl. Oral Sci. 21 (2013) 320-326.

[10] H. Shimizu, K.S. Kurtz, Y. Tachii, Y. Takahashi, Use of metal conditioners to improve bond strengths of autopolymerizing denture base resin to cast Ti-6Al-7Nb and CoCr, J. Dent. 34 (2006) 117-122.

[11] T. Jemt, J. Johansson, Implant treatment in the edentulous maxillae: a 15-year follow-up study on 76 consecutive patients provided with fixed prostheses, Clin. Implant. Dent. Relat. Res. 8 (2006) 61-69.

[12] T. Bozini, H. Petridis, K. Garefis, P. Garefis, A meta-analysis of prosthodontic complication rates of implant-supported fixed dental prostheses in edentulous patients after an observation period of at least 5 years, Int. J. Oral Maxillofac. Implants 26 (2011) 304-318.

[13] G.J. Han, S.N. Chunq, B.H. Chun, C.K. Kim, K.H. Oh, B.H. Cho, Effect of the applied power of atmospheric pressure plasma on the adhesion of composite resin to dental ceramic, J. Adhes. Dent. 14 (2012) 461-469.

[14] A.J. Vechiato Filho, D.M. dos Santos, M.C. Goiato, R.A. de Medeiros, A. Moreno, R. Bonatto Lda, E.C. Rangel, Surface characterization of lithium disilicate ceramic after nonthermal plasma treatment, J. Prosthet. Dent. 112 (2014) 1156-1163.

[15] G.B. Valverde, P.G. Coelho, M.N. Janal, F.C. Lorenzoni, R.M. Carvalho, V.P. Thompson, K.D. Weltemann, N.R. Silva, Surface characterization and bonding of Y-TZP following non-thermal plasma treatment, J. Dent. 41 (2013) 51-59.
[16] T. Hayakawa, M. Yoshinari, K. Nemoto, Characterization and protein-adsorption behavior of deposited organic thin film onto titanium by plasma polymerization with hexamethyldisiloxane, Biomaterials 25 (2004) 119-127.

[17] N.C. Cruz, E.C. Rangel, G.Z. Gadioli, R.P. Mota, R.Y. Honda, M.A. Algatti, W.H. Schreiner, The influence of plasma composition on the properties of plasma treated biomaterials, MRS Proc. 672 (2001) 03.35, http://dx.doi.org/10.1557/PROC-672-03. 35.

[18] R.C.C. Rangel, T.C. Pompeu, J.L S. Barros Jr C.A. Antonio, N.M. Santos, B.O. Pelici, C.M.A. Freire, N.C. Cruz, E.C. Rangel, Improvement of the corrosion resistance of carbon steel by plasma deposited thin films, in: R.S. Razavi (Ed.), Recent Researches in Corrosion Evaluation and Protection, vol. 1, InTech, Rijeka. Croatia 2012, pp. 91-116.

[19] S.A. Pihan, T. Tsukruk, R. Förch, Plasma polymerized hexamethyl disiloxane in adhesion applications, Surf. Coat. Technol. 203 (2009) 1856-1862.

[20] X. Ye, L. Wang, Z.T. Tse, G. Tang, G. Song, Effects of high-energy electro-pulsing treatment on microstructure, mechanical properties and corrosion behavior of Ti-6Al4V alloy, Mater. Sci. Eng., C 49 (2015) 851-860.

[21] X. Ye, Z.T. Tse, G. Tang, G. Song, Mechanical properties and phase transition of biomedical titanium alloy strips with initial quasi-single phase state under highenergy electropulses, J. Mech. Behav. Biomed. Mater. 42 (2015) 100-115.

[22] P. Magne, M.P. Paranhos, L.H. Burnett Jr., New zirconia primer improves bond strength of resin-based cements, Dent. Mater. 26 (2010) 345-352.

[23] T. Derand, M. Molin, K. Kvam, Bond strength of composite luting cement to zirconia ceramic surfaces, Dent. Mater. 21 (2005) 1158-1162.

[24] S. Li, J. Ni, X. Liu, X. Zhang, S. Yin, M. Rong, Z. Guo, L. Zhou, Surface characteristics and biocompatibility of sandblasted and acid-etched titanium surface modified by ultraviolet irradiation: an in vitro study, J. Biomed. Mater. Res. B Appl. Biomater. 100 (2012) 1587-1598

[25] D.B. Barbosa, D.R. Monteiro, V.A. Barão, A.C. Pero, M.A. Compagnoni, Effect of monomer treatment and polymerisation methods on the bond strength of resin teeth to denture base material, Gerodontology 26 (2009) 225-231.

[26] D.B. Barbosa, V.A. Barão, D.R. Monteiro, M.A. Compagnoni, J. Marra, Bond strength of denture teeth to acrylic resin: effect of thermocycling and polymerisation methods, Gerodontology 25 (2008) 237-244.

[27] C.Y. Guo, A.T. Hong Tang, J.K. Hon Tsoi, J.P. Matinlinna, Effects of different blasting materials on charge generation and decay on titanium surface after sandblasting, J. Mech. Behav. Biomed. Mater. 32 (2014) 145-154.

[28] J. Lowell, A.C. Rose-Innes, Contact electrification, Adv. Phys. 29 (1980) 947-1023.

[29] M. Taborelli, M. Jobin, P. François, P. Vaudaux, M. Tonetti, S. Szmukler-Moncler, J.P. Simpson, P. Descouts, Influence of surface treatments developed for oral implants on the physical and biological properties of titanium. (I) Surface characterization, Clin. Oral Implants Res. 8 (1997) 208-216.

[30] F. Rupp, R.A. Gittens, L. Scheideler, A. Marmur, B.D. Boyan, Z. Schwartz, J. GeisGerstorfer, A review on the wettability of dental implant surfaces I: theoretical and experimental aspects, Acta Biomater. 10 (2014) 2894-2906.

[31] E.C. Rangel, N.M. dos Santos, J.R.R. Bortoleto, S.F. Durrant, W.H. Schreiner, R.Y Hondac, R.C.C. Rangel, N.C. Cruz, Treatment of PVC using an alternative low energy ion bombardment procedure, Appl. Surf. Sci. 258 (2011) 1854-1861.

[32] M. Mazur, M. Kalisz, D. Wojcieszak, M. Grobelny, P. Mazur, D. Kaczmarek, J Domaradzki, Determination of structural, mechanical and corrosion properties of $\mathrm{Nb}_{2} \mathrm{O}_{5}$ and (NbyCu 1-y) ox thin films deposited on $\mathrm{Ti}_{6} \mathrm{Al}_{4} \mathrm{~V}$ alloy substrates for dental implant applications, Mater. Sci. Eng., C 47 (2015) 211-221.

[33] V.A. Barão, M.T. Mathew, W.G. Assunção, J.C. Yuan, M.A. Wimmer, C. Sukotjo, Stability of cp-Ti and Ti-6Al-4V alloy for dental implants as a function of saliva $\mathrm{pH}-$ an electrochemical study, Clin. Oral Implants Res. 23 (2012) 1055-1062.

[34] L.P. Faverani, W.G. Assunção, P.S. de Carvalho, J.C. Yuan, C. Sukotjo, M.T. Mathew, V.A. Barao, Effects of dextrose and lipopolysaccharide on the corrosion behavior of a Ti-6Al-4V alloy with a smooth surface or treated with double-acid-etching, PLoS One 9 (2014) e93377.

[35] K.B. May, J. Fox, M.E. Razzoog, B.R. Lang, Silane to enhance the bond between polymethyl methacrylate and titanium, J. Prosthet. Dent. 73 (1995) 428-431.

[36] H.S. An, J.-M. Park, E.-J. Park, Evaluation of shear bond strengths of gingiva-colored composite resin to porcelain, metal and zirconia substrates, J. Adv. Prosthodont. 3 (2011) 166-171.

[37] Y.A. Elzarug, R.B. Galburt, A. Ali, M. Finkelman, H.G. Dam, An in vitro comparison of the shear bond strengths of two different gingiva-colored materials bonded to commercially pure titanium and acrylic artificial teeth, J. Prosthodont. 23 (2014) 313-319.

[38] O. Alageel, M.N. Abdallah, Z.Y. Luo, J. Del-Rio-Highsmith, M. Cerruti, F. Tamimi, Bonding metals to poly(methyl methacrylate) using aryldiazonium salts, Dent. Mater. 31 (2015) 105-114.

[39] A.C. Popa, G.E. Stan, M.A. Husanu, I. Pasuk, I.D. Popescu, A.C. Popescu, IN. Mihailescu, Multi-layer haemocompatible diamond-like carbon coatings obtained by combined radio frequency plasma enhanced chemical vapor deposition and magnetron sputtering, J. Mater. Sci. Mater. Med. 24 (2013) 2695-2707.

[40] F. Chai, N. Mathis, N. Blanchemain, C. Meunier, H.F. Hildebrand, Osteoblast interaction with DLC-coated Si substrates, Acta Biomater. 4 (2008) 1369-1381. 